\title{
Cannabis use before age 15 and subsequent executive functioning
}

Maria Alice Fontes, Karen I. Bolla, Paulo Jannuzzi Cunha, Priscila Previato Almeida,

Flávia Jungerman, Ronaldo Ramos Laranjeira, Rodrigo A. Bressan and Acioly L. T. Lacerda

\section{Background}

Many studies have suggested that adolescence is a period of particular vulnerability to neurocognitive effects associated with substance misuse. However, few large studies have measured differences in cognitive performance between chronic cannabis users who started in early adolescence (before age 15) with those who started later

\section{Aims}

To examine the executive functioning of individuals who started chronic cannabis use before age 15 compared with those who started chronic cannabis use after 15 and controls.

\section{Method}

We evaluated the performance of 104 chronic cannabis users (49 early-onset users and 55 late-onset users) and 44 controls who undertook neuropsychological tasks, with a focus on executive functioning. Comparisons involving neuropsychological measures were performed using generalised linear model analysis of variance (ANOVA)

\section{Results}

The early-onset group showed significantly poorer performance compared with the controls and the late-onset group on tasks assessing sustained attention, impulse control and executive functioning.

\section{Conclusions}

Early-onset chronic cannabis users exhibited poorer cognitive performance than controls and late-onset users in executive functioning. Chronic cannabis use, when started before age 15 , may have more deleterious effects on neurocognitive functioning.

\section{Declaration of interest}

None.
Studies have demonstrated neuropsychological deficits associated with acute exposure to cannabis. ${ }^{1,2}$ However, results from studies examining persistent cognitive impairments associated with chronic cannabis use are contradictory, with some studies, ${ }^{3,4}$ but not all, ${ }^{5,6}$ showing significant neuropsychological deficits even after some weeks of abstinence. One possible explanation for these inconsistent findings is that cannabis is more neurotoxic for some populations than for others. Individuals who are exposed to potentially neurotoxic substances before age 15 , while the brain is still developing, ${ }^{7}$ may be at higher risk of developing persistent neuropsychological deficits compared with older individuals. One model of genetic control postulates that species with delayed brain development have a larger relative volume of later-developing structures (for example cortical areas, particularly the prefrontal cortex). Consequently, later-developing structures interact with environmental factors for prolonged postnatal periods, which can importantly contribute to the tuning and shaping of circuitry. Prefrontal cortex anatomical development continues after birth with full maturation being achieved only around the early $20 \mathrm{~s} .{ }^{8}$ In addition, different areas within the prefrontal cortex mature at different times. This area of the brain encompasses a number of distinct cognitive processes with different developmental trajectories, including planning, verbal fluency, complex problemsolving and impulse control. ${ }^{9}$

Studies have suggested that adolescence is a period of particular vulnerability to development of neurocognitive effects associated with substance use. ${ }^{10-12}$ Findings from animal studies have suggested that cannabinoid $1 \quad\left(\mathrm{CB}_{1}\right)$ receptor levels peak in early adolescence ${ }^{13}$ and animals exposed to cannabis in adolescence are more vulnerable to learning impairments compared with animals exposed in adult life. Medina et al demonstrated that after a month of abstinence, adolescent cannabis users showed slower psychomotor speed, poorer complex attention and memory skills, and degraded planning/sequencing abilities compared with
34 non-users. ${ }^{14}$ Furthermore, there was an inverse correlation between lifetime marijuana exposure and cognitive performance in the same cognitive domains, suggesting a dose-dependent effect. The authors conclude that frequent marijuana use during adolescence may negatively influence neuromaturation and cognitive development. Wilson et al evaluated the possible role of age on first use of cannabis interfering with brain and body development. ${ }^{15}$ Brain volume measurements (whole brain, grey matter, white matter and lateral ventricle volumes) and global cerebral blood flow were evaluated in 57 chronic cannabis users. Participants who started using cannabis before age 17 had smaller total brain and cortical grey matter volumes with larger white matter volumes. Both males and females who started regular early use were physically smaller in height and weight, with greater effects in males.

Executive functioning is a term that refers to complex mental control processes reflected in future-oriented behaviour that includes cognitive flexibility in problem-solving, focused attention, inhibition of impulsive responses, monitoring, evaluating and adjusting self-directed perception and working memory. From a neurophysiological point of view, executive functions mainly rely on circuits involving prefrontal areas. ${ }^{16}$ According to DSM-IV, ${ }^{17}$ compulsive use and intense, persistent desire to use a substance, despite the presence of physical and psychological consequences related to the substance use, is a core symptom of dependence syndrome. In this sense, executive deficits might play a central role in the development of addictive behaviours and, consequently, in substance use disorder treatment issues. $^{18}$

Undoubtedly, adolescents are vulnerable to impaired cognitive effects associated with cannabis misuse. ${ }^{19}$ The results suggest that chronic cannabis users process complex information more slowly and performance worsens in cognitive overload tasks as lifetime consumption increases. ${ }^{20}$ With this in mind, we examined the 
impact on executive functioning in 104 chronic cannabis users who were seeking treatment at the Drug and Alcohol Unit (UNIAD) of the University of São Paulo. Because of the unusually large sample size, we were able to divide the chronic cannabis users into two groups based on age of initial use. Our main aim was to examine executive functioning of individuals who started chronic cannabis use before age 15 (early-onset group) compared with individuals who started chronic cannabis use after age 15 (late-onset group) and controls (non-users). We hypothesised that the early-onset group would perform poorly on cognitive tests evaluating executive functioning compared with both the late-onset group and the healthy controls.

\section{Method}

\section{Participants}

We recruited chronic cannabis users who were seeking treatment at the Substance Use Disorder Program, Federal University of São Paulo. To assess study eligibility, telephone screening interviews were administered to all potential participants. After enrolment in the study, participants were interviewed to provide a complete medical and psychiatric history. Although abstinence was encouraged, it was not required. All participants participate in a day-long interview in order to start treatment at UNIAD. The neuropsychological assessment was performed on the first day of the treatment.

The following inclusion criteria were used for chronic cannabis users: males and females, aged 18 to 55 years, with DSM-IV cannabis misuse or dependence (cannabis as the misuse substance of choice) as determined by Composite International Diagnostic Interview (CIDI). ${ }^{21}$ Exclusion criteria included current history of other DSM-IV Axis I disorders, with the exception of nicotine-related disorders as determined by CIDI; current use of psychoactive medications, history of head trauma with loss of consciousness for more than $5 \mathrm{~min}$, intellectual disability or estimated IQ below 80, and non-correctable vision or hearing impairment.

Individuals in the control group qualified for this study if they were between the ages of 18 and 55, did not use any psychoactive substance, did not have a history of head trauma, and had no lifetime diagnosis of Axis I DSM-IV disorders. They had not used cannabis at all in the last 3 months and had been exposed no more than five times in their lifetime. The study protocol was approved by the local institutional review board. All participants were required to sign a written informed consent, in accordance with the Federal University of São Paulo review board.

\section{Instruments}

A detailed assessment was administered at enrolment consisting of a semi-directed protocol measuring psychosocial functioning, medical history and history of substance use. We used the modified Time Line Follow Back calendar (TLFB) ${ }^{22}$ to obtain detailed information regarding type, amount, and frequency of substance exposure. Composite International Diagnostic Interviews were used to assess DSM-IV Axis I diagnosis. Urine analyses for tetrahydrocannabinol detection were performed on all participants on the same day as the interview to evaluate the reliability of what they reported in the interview. Tests were not performed to detect other substances.

The neuropsychological battery consisted of the following.

(a) Stroop Test - Victoria Version, composed of three cards, each one containing six rows of four items. ${ }^{23}$ The first card contains 24 rectangles filled with colours (green, pink, blue and brown). The participant should name as quickly as possible the printed colours. The second card has nouns written in coloured words and the participant is required to name as quickly as possible the colour of the words, disregarding their verbal content (for example the participant is expected to respond green when the word 'each', written in green, is presented). On the third card, the coloured stimuli are colour names, so that the printed colour never corresponds to the colour name (for example 'Brown' is written in blue ink). This later task, thus, requires the individual to inhibit an automatic reading response and to produce a more effortful colour-naming response by exerting an inhibitory control.

(b) Wisconsin Card Sorting Test - version 64 (planning, executive functioning, conceptualisation, perseveration, and ability to form abstract concepts). ${ }^{24}$

(c) Frontal Assessment Battery - FAB, a short neuropsychological instrument aimed at assessing executive functions. ${ }^{25}$ The FAB consists of six subtests, each exploring functions related to frontal functioning: conceptualisation (similarities task), mental flexibility (phonological fluency task), motor programming (by means of Luria's motor series), sensitivity to interference (conflicting instructions task), inhibitory control (go/nogo task) and environmental autonomy (evaluation of prehension behaviour).

(d) Vocabulary and block design (Wechsler Adult Intelligence Scale - Revised (WAIS-R)) for IQ estimation. ${ }^{26}$ Vocabulary is a WAIS-R subtest that evaluates the degree to which one has learned, been able to comprehend and verbally express vocabulary; there are 35 words. Block design is a subtest that measures visuospatial and motor skills. In the test the participant has to take blocks that have all white sides, all red sides, and red and white sides and arrange them according to a pattern. They are timed on this task and compared to a normative sample. Estimates of full-scale IQ were made using vocabulary and block design. ${ }^{27}$

\section{Statistical analyses}

For primary analysis, we divided the sample of chronic cannabis users into two groups: the early-onset group, who initiated use of cannabis before the age of 15; and the late-onset group, who initiated use of cannabis at the age of 15 or later. The mean age of first use was 16.6 (s.d.=3.5) years. However, we chose 15 years as the cut-off in order to stress the impact of cannabis exposure in early adolescence as opposed to late adolescence. This was possible because of the large sample size (104 participants) and wide range of age of first use (8 to 30 years).

We compared the demographic characteristics of both the early- and late-onset groups with those of the controls using Student's $t$-test (for variables with normal distribution) or Mann-Whitney $U$-test. We used Student's $t$-test to compare age of first use, age starting daily use, pattern of use, years of daily use, estimation of life consumption, and days of abstinence in early-onset and late-onset groups.

Comparisons involving neuropsychological measures were performed using generalised linear model analysis of variance (ANOVA). In order to minimise the problem of multiple comparisons in neuropsychological analyses, we decided to select only the more relevant measures according to the literature for each test. For example, for the WCST, we limited analyses to two measures (number of correct categories and perseverative errors). The alpha level was set at $P<0.05$ (two-tailed) for all analyses. 


\section{Results}

In total 148 (participants including 44 controls) were enrolled in the study. Of the 104 chronic cannabis users, 55 initiated use of cannabis before the age of 15 . The three groups were matched for age, years of education, and IQ (Student's $t$-test, $P>0.05$ ), differing only in gender. There were more males in the early-onset group $(72.7 \%)$ and the late-onset group $(83.7 \%)$ than in the control group $(45.5 \%)$ (Student's $t$-test, $P<0.001)$. Sociodemographic data are summarised in Table 1.

Those in the early-onset group were abstinent for 4.1 (s.d. =6.9) days at the time of assessment, whereas the late-onset group were abstinent for 3.8 (s.d. $=5.6)$ days $(P>0.05)$. The early-onset group was first exposed to cannabis at the age of 13.9 (s.d. = 1.5) years and progressed to daily use at the age of 19.3 (s.d. $=6.3$ ) years $(5.4$ years later). The late-onset group began cannabis use at the age of 18.4 (s.d. $=2.8$ ) years and started daily use at the age of 21.2 (s.d.=3.8) years (2.8 years later). The estimated average lifetime consumption for the early-onset group was 6790 joints; for the late-onset group it was 5160 joints, as calculated using the TLFB (Table 2).

There were no differences in IQ, vocabulary or block design results when comparing the early-onset, late-onset, and control groups (Table 3 ). The early-onset group had more perseverative errors $(10$ (s.d. $=6.63)$ v. $6.44($ s.d. $=3.52), F=5.18, P=0.001)$ and completed fewer categories $(2.77 \quad($ s.d. $=1.32)$ v. 3.5 (s.d.=1.28), $F=4.12, P=0.008)$ on the WCST compared with controls (Figs 1 and 2). On the Stroop test, card (noun-colour), the early-onset group also performed poorly compared with controls $(18.20$ (s.d. $=5.82)$ v. 15.64 (s.d. $=2.96$, Fig. 3$), F=3.50$, $P=0.006)$. Performance on the FAB was poorer in the early-onset group $(15.85$ (s.d. $=2.41))$ in comparison with both the late-onset (16.82 (s.d. =1.25), $F=5.17, P=0.014$ ) and the control group (17.09 (s.d. =1.11), $F=7.01, P=0.002$, Fig. 4). Neuropsychological data are summarised in Tables 3 and 4. Comparisons involving late-onset and control groups were non-significant.

\section{Discussion}

\section{Main findings}

This study evaluated the neurocognitive functioning of early- and late-onset chronic cannabis users and controls. The early-onset, but not the late-onset, group performed poorly on selected executive tasks compared with controls. In addition, the earlyonset group performed poorly on the FAB compared with both the late-onset and the control groups. Our findings indicate that early-onset chronic cannabis users are cognitively impaired compared with controls, suggesting that early exposure to cannabis is associated with more adverse effects on the brain. These results are in line with previous studies examining cognitive effects associated with early cannabis exposure. ${ }^{28-30}$

\begin{tabular}{lcccc} 
Table 1 Demographic information & $\begin{array}{c}\text { Early-onset group } \\
(n=55)\end{array}$ & $\begin{array}{c}\text { Late-onset group } \\
(n=49)\end{array}$ & $\begin{array}{c}\text { Control group } \\
(n=44)\end{array}$ & $P$ \\
& $30.4(8.3)$ & $30.0(4.1)$ & $27.8(8.0)$ & NS \\
\hline Age, years: mean (s.d.) & 72.7 & 83.7 & 45.5 & $<0.001$ \\
\hline Gender, males: \% & $99.1(8.6)$ & $98.1(8.8)$ & $100.0(9.8)$ & NS \\
\hline Estimated IQ, mean (s.d.) & $12.4(3.0)$ & $13.6(3.5)$ & $14.0(2.6)$ & NS \\
\hline Years of education, mean (s.d.) & & & & \\
NS, Not statistically significant $(P \geqslant 0.05)$. & & &
\end{tabular}

\begin{tabular}{|lccc|}
\hline Table 2 Information about use of cannabis by group & $\begin{array}{c}\text { Early-onset group } \\
(n=55)\end{array}$ & $\begin{array}{c}\text { Late-onset group } \\
(n=49)\end{array}$ & $P$ \\
\hline Age of first use, years: mean (s.d.) & $13.9(1.5)$ & $18.4(2.8)$ & $<0.001$ \\
\hline Age of daily use, years: mean (s.d.) & $19.3(6.3)$ & $21.2(3.8)$ & NS \\
\hline Pattern of use, joints/day: mean (s.d.) & $1.7(1.5)$ & $1.5(1.7)$ & NS \\
\hline Years of daily use: mean (s.d.) & $10.9(8.0)$ & 5160 & NS \\
\hline Lifetime consumption & 6790 & $3.8(5.6)$ & NS \\
\hline Days of abstinence: mean (s.d.) & $4.1(6.9)$ & & \\
\hline NS, Not statistically significant $(P \geqslant 0.05)$ & & & \\
\hline
\end{tabular}

Table 3 Descriptive statistics of vocabulary, block design and IQ estimation by group

\begin{tabular}{|c|c|c|c|c|c|c|c|}
\hline & \multicolumn{3}{|c|}{ Groups, mean (s.d.) } & \multicolumn{3}{|c|}{$t$-test, $P$} & \multirow[b]{2}{*}{$\begin{array}{l}\text { ANOVA, } \\
P\end{array}$} \\
\hline & $\begin{array}{l}\text { Early-onset group } \\
\qquad(n=55)\end{array}$ & $\begin{array}{l}\text { Late-onset group } \\
\qquad(n=49)\end{array}$ & $\begin{array}{l}\text { Control group } \\
\qquad(n=44)\end{array}$ & $\begin{array}{l}\text { Early-onset } v \text {. } \\
\text { control groups }\end{array}$ & $\begin{array}{l}\text { Late-onset } v \text {. } \\
\text { control groups }\end{array}$ & $\begin{array}{l}\text { Early-onset } v \text {. } \\
\text { late-onset groups }\end{array}$ & \\
\hline \multicolumn{8}{|l|}{ WAIS-R } \\
\hline Vocabulary & $43.67(8.22)$ & 43.71 (8.21) & $45.72(7.08)$ & 0.193 & 0.212 & 0.980 & 0.361 \\
\hline Block design & $32.36(9.53)$ & $32.20(9.50)$ & $31.27(10.63)$ & 0.592 & 0.657 & 0.932 & 0.846 \\
\hline Estimated IQ & 99.09 (8.64) & 98.18 (8.82) & $100.02(9.82)$ & 0.617 & 0.344 & 0.598 & 0.622 \\
\hline
\end{tabular}




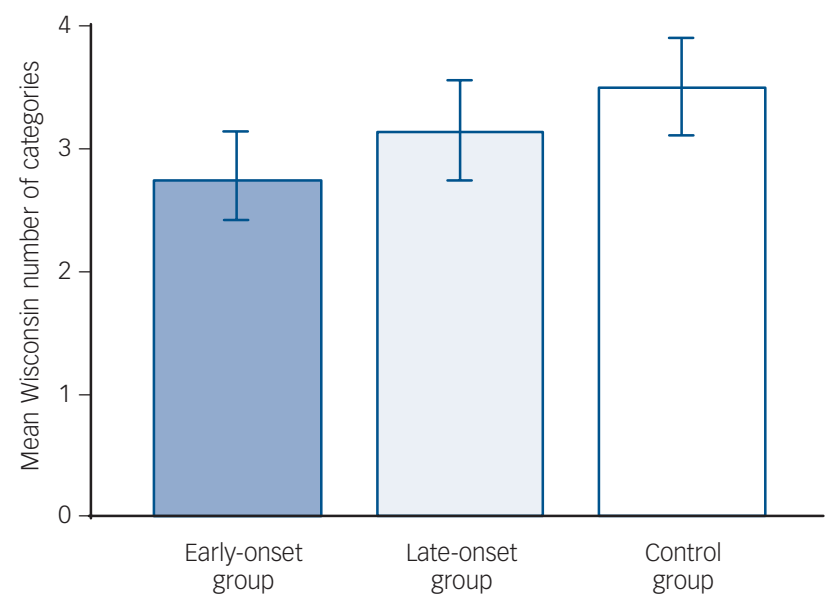

Fig. 1 Wisconsin Card Sorting Test number of categories in early-onset, late-onset and control groups.

Error bars: 95\% confidence intervals.

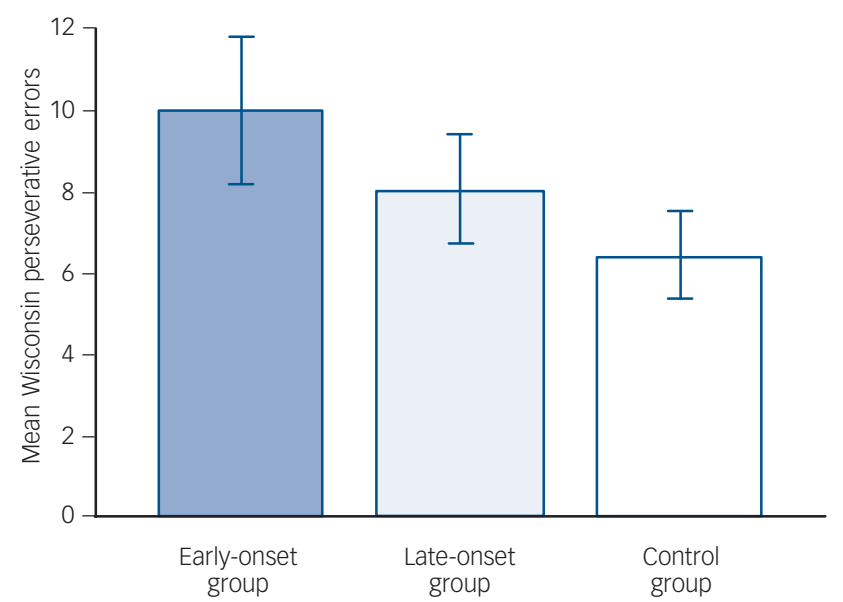

Fig. 2 Wisconsin Card Sorting Test perseverative errors in early-onset, late-onset and control groups.

Error bars: $95 \%$ confidence intervals.

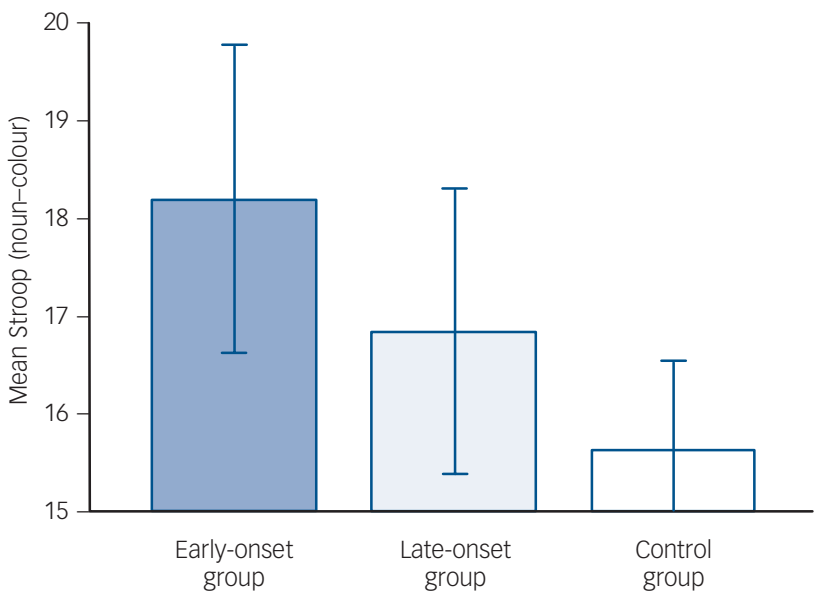

Fig. 3 Stroop Test (noun-colour) time in seconds in early-onset, late-onset and control groups.

Error bars: 95\% confidence intervals.

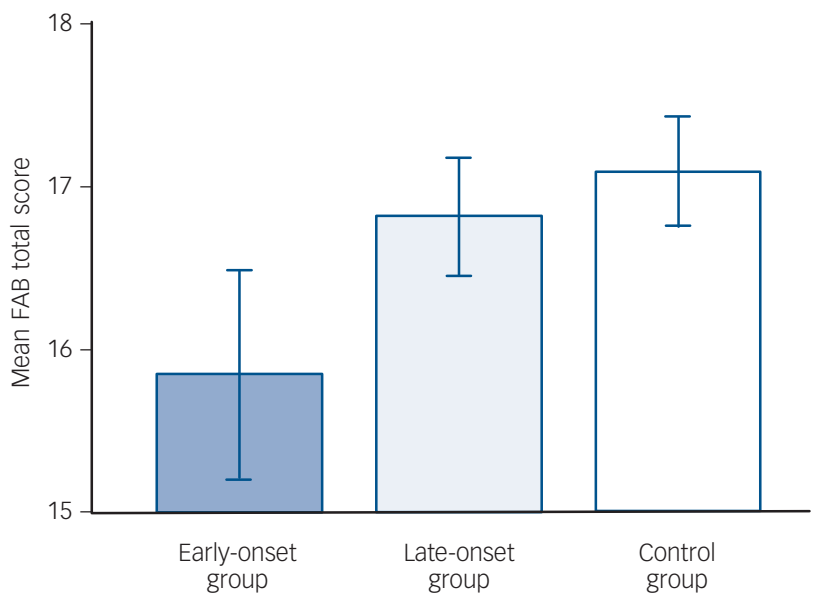

Fig. 4 Frontal Assessment Battery (FAB) total score in early-onset, late-onset and control groups.

Error bars: 95\% confidence intervals.

\begin{tabular}{|c|c|c|c|c|c|c|c|c|}
\hline & \multicolumn{3}{|c|}{ Groups, mean (s.d.) } & \multicolumn{3}{|c|}{$t$-test, $P$} & \multicolumn{2}{|c|}{ ANOVA } \\
\hline & $\begin{array}{l}\text { Early-onset group } \\
\qquad(n=55)\end{array}$ & $\begin{array}{l}\text { Late-onset group } \\
\qquad(n=49)\end{array}$ & $\begin{array}{l}\text { Control group } \\
\qquad(n=44)\end{array}$ & $\begin{array}{l}\text { Early-onset } v \text {. } \\
\text { control groups }\end{array}$ & $\begin{array}{l}\text { Late-onset } v \text {. } \\
\text { control groups }\end{array}$ & $\begin{array}{l}\text { Early-onset } v \text {. } \\
\text { late-onset groups }\end{array}$ & $F$ & $P$ \\
\hline $\begin{array}{l}\text { Wisconsin Card } \\
\text { Sorting Test }\end{array}$ & & & & & & & & \\
\hline $\begin{array}{l}\text { Categories }^{a} \\
\text { Perseverative }\end{array}$ & $2.77(1.32)$ & $3.16(1.34)$ & 3.5 (1.28) & 0.008 & 0.221 & 0.161 & 3.665 & 0.028 \\
\hline errors $^{b}$ & $10.00(6.63)$ & 8.09 (4.53) & $6.44(3.52)$ & 0.001 & 0.061 & 0.095 & 5.644 & 0.004 \\
\hline $\begin{array}{l}\text { Frontal } \\
\text { Assessment }\end{array}$ & & & & & & & & \\
\hline Battery $^{a}$ & $15.85(2.41)$ & $16.82(1.25)$ & $17.09(1.11)$ & 0.002 & 0.270 & 0.014 & 7.014 & 0.001 \\
\hline $\begin{array}{l}\text { Stroop } \\
\text { (noun-colour) }^{c}\end{array}$ & $18.20(5.82)$ & $16.85(4.96)$ & $15.64(2.96)$ & 0.006 & 0.164 & 0.215 & 3.464 & 0.034 \\
\hline
\end{tabular}




\section{Implications of early cannabis use}

In the past few decades, a steady increase in people seeking treatment for cannabis-related problems has been registered in Western countries, with an associated decrease in the age of first cannabis use. ${ }^{31}$ Adolescence is a period in which the brain appears to be particularly vulnerable to the neurotoxic effects of cannabis. Mounting evidence has associated cannabis use with psychiatric morbidity, such as depression and psychosis, and the strength of this association appears to be highly influenced by age at first exposure. $^{32}$

Cannabis exposure during adolescence may potentially be associated with long-lasting neuronal consequences. Crosssectional and longitudinal structural brain imaging studies have revealed that the brain before age 15 is under a complex process of biological maturation, especially in the prefrontal cortex, which has peak grey matter volumes at age 11, which is then followed by rapid grey matter loss in late adolescence. ${ }^{33}$ During adolescence, rapid changes in neural organisation occur, including a reduction in the number of synapses in cortical and subcortical structures as well as changes in neurotransmitter and receptor levels. ${ }^{34}$ It has been further suggested that these changes in central nervous system organisation may make the brain uniquely vulnerable to insults by substances of misuse. ${ }^{35}$ Early cannabis use was found to be strongly associated with misuse and dependence during adolescence; thus, it may be both more 'addicting' and cause greater effects. ${ }^{36}$ Ehrenreich et al evaluated a broad spectrum of attentional functions in 99 marijuana users, with a computerised battery. ${ }^{28}$ They studied 48 participants exposed to cannabis before 16 years of age, 51 who first used cannabis after the age of 16, and 49 controls. Associations involving visual attention measures and age of first exposure to cannabis were found, suggesting that exposure to marijuana during adolescence may lead to persistent attentional deficits.

Taken together, those findings suggest that exposure to exogenous cannabinoids in critical periods of brain development, including early adolescence, may be more neurotoxic. In the postnatal brain, endocannabinoids act as retrograde messengers to regulate the function of many synapses. Furthermore, several maturational events appear to depend on the modulatory influence of the endocannabinoid system in these critical periods. $^{37}$ Dysregulation of these fine-tuned developmental processes may underlie both cognitive impairments and psychopathology associated with early exposure to cannabis use. ${ }^{19}$ Alternatively, the present findings may be accounted for by previous cognitive impairments in the early-onset group, which would make individuals in this group more prone to exposure to substances at an early age. This hypothesis, however, appears not to be supported by the present findings since the three groups were matched for estimated IQ and a measure of premorbid functioning assessed by vocabulary (the WAIS-R).

The early-onset group showed a particularly poor performance in the $\mathrm{FAB}$, and revealed deficits in comparison with both the late-onset and the control groups. The FAB is a short neuropsychological battery aimed at assessing conceptualisation, mental flexibility, programming, sensitivity to interference, inhibitory control and environmental autonomy. Its results have been shown to significantly correlate with medial and dorsolateral prefrontal activity as measured by neurofunctional brain imaging studies. ${ }^{38,39}$ Performance on the six subtests of the FAB provides a composite global score that evaluates the severity of the dysexecutive syndrome affecting both cognition and motor function. ${ }^{25}$ In addition, the poor performance of the early-onset group on the Stroop test and perseverative responding (as measured by the WCST) suggest that exposure to cannabis in early adolescence may lead to lower mental flexibility. This could explain partially why chronic users find it difficult to maintain treatment and to discontinue substance use despite evident physical and psychological consequences.

Aharonovich et al suggest that mild cognitive impairments negatively affect retention in out-patient cognitive-behavioural therapy treatment for cocaine dependence. ${ }^{40}$ Cognitive deficits, particularly in executive functioning, have been associated with poorer adherence to treatment in several studies. ${ }^{41,42}$ In this sense, executive deficits appear to negatively affect treatment outcome and may represent a potentially important aspect for designing specific or target-orientated cognitive strategies for treatment of substance use disorders, especially for those who initiated use at an early age. ${ }^{43}$

We did not find differences in executive functioning performance when comparing the late-onset and control groups. Another important issue is whether starting cannabis use at a later age is inoffensive to cognition. It is possible that participants who start to use cannabis at a later age may use different neural networks and compensate for their deficits more than individuals who initiated the use of cannabis at an earlier stage of brain development. Chang et al showed that the brain network might be altered in some cannabis users but without an apparent change in cognition. ${ }^{44}$ The long-term chronic effects of marijuana on the altered brain network may be reversible with prolonged abstinence. A plausible explanation for this is that the brain, in response to chronic cannabis use, appears to undergo neuroadaptation by accessing compensatory processes in order to maintain usual cognitive performance. ${ }^{45}$ Future studies should focus on neurocognitive tasks including decision-making; this is a core part of the executive dysfunction now understood to be one of the hallmark features of addiction that also includes impaired impulse dysregulation.

\section{Limitations}

The findings from the present study should be interpreted with caution while considering the following limitations. First, the cross-sectional study design does not allow us to make any conclusions about causality. Some executive deficits are explicitly found, but it is not possible to establish whether they are the consequences of cannabis use or were present before first use. Second, the present study evaluated cannabis users in a period of early abstinence. At least in part, the results may be related to substance residues or withdrawal symptoms. ${ }^{46}$ This effect was minimised because both the cannabis user groups (early and late onset) were matched for pattern of use, years of daily use, life consumption and days of abstinence. Third, these two groups were predominantly composed of males whereas the control group had equal numbers of males and females. However, the early- and late-onset groups were matched for gender and the early-onset group performed poorly on the FAB compared with both the late-onset and control groups. Yet, the results did not change when only males were analysed.

In conclusion, our findings suggest that early-onset, but not late-onset, chronic cannabis users exhibit executive deficits. Although the underlying mechanisms are not fully understood, cannabis exposure at an early age may have greater deleterious effects on neurocognitive functioning. Future longitudinal studies examining adolescents who initiated cannabis use recently may be especially informative

\section{Acknowledgements}

We thank Bo Williams for help in the preparation and editing of the manuscript. 
Maria Alice Fontes, PhD, Laboratório Interdisciplinar de Neurociências Clínicas and Unidade de Pesquisas em Álcool e Drogas, Departamento de Psiquiatria, Universidade Federal de São Paulo, São Paulo, Brazil; Karen I. Bolla PhD, Department of Neurology, Johns Hopkins University School of Medicine, Baltimore, USA; Paulo Jannuzzi Cunha, PhD, Programa Equilibrium, Departamento de Psiquiatria, Faculdade de Medicina da Universidade de São Paulo, São Paulo, Brazil Priscila Previato Almeida, Laboratório Interdisciplinar de Neurociências Clínicas and Unidade de Pesquisas em Álcool e Drogas, Departamento de Psiquiatria, Universidade Federal de São Paulo, São Paulo, Brazil; Flávia Jungerman, PhD, Ronaldo Ramos Laranjeira, MD, Unidade de Pesquisas em Álcool e Drogas, Departamento de Psiquiatria, Universidade Federal de São Paulo, são Paulo, Brazi Rodrigo A. Bressan $M$ Departamento de Psiquiatria, Universidade Federal de São Paulo, São Paulo, Brazi Acioly L. T. Lacerda, MD, Laboratório Interdisciplinar de Neurociências Clínicas, Departamento de Psiquiatria, Universidade Federal de São Paulo, Instituto Sinapse de Neurociências Clínicas and Centro de Pesquisa e Ensaios Clínicos Sinapse-Bairral, São Paulo, Brazi

Correspondence: Maria Alice Fontes, Rua Dr José Gustavo Busch, 155-121B Morumbi, São Paulo SP Brazil, ZIP 05705-190. Email: m.alice@plenamente.com.br

First received 11 Jan 2010, final revision 28 Sep 2010, accepted 15 Dec 2010

\section{References}

1 Ramaekers JG, Kauert G, Theunissen EL, Toennes SW, Moeller MR Neurocognitive performance during acute THC intoxication in heavy and occasional cannabis users. J Psychopharmacol 2009; 23: 266-77.

2 Ranganathan M, D'Souza DC.The acute effects of cannabinoids on memory in humans: a review. Psychopharmacology (Berl) 2006; 188: 425-44.

3 Bolla KI, Brown K, Eldreth D, Tate K, Cadet JL. Dose-related neurocognitive effects of marijuana use. Neurology 2002; 59: 1337-43.

4 Solowij N. Do cognitive impairments recover following cessation of cannabis use? Life Sci 1995; 56: 2119-26.

5 Harrison GP Jr, Gruber AJ, Hudson Jl, Huestis MA, Yurgelun-Todd D. Cognitive measures in long-term cannabis users. J Clin Pharmacol 2002; 42: s41-7.

6 Pope HG Jr. Cannabis, cognition, and residual confounding. JAMA 2002; 287: 1172-74.

7 Giedd JN, Blumenthal J, Jeffries NO, Castellanos FX, Liu H, Zijdenbos, A, et al. Brain development during childhood and adolescence: a longitudinal MRI study. Nat Neurosci 1999; 2; 861-3.

8 Ellgren M, Artmann A, Tkalych O, Gupta A, Hansen HS, Hansen SH, et al. Dynamic changes of the endogenous cannabinoid and opioid mesocorticolimbic systems during adolescence: THC effects. Eur Neuropsychopharmacol 2008; 18: 826-34.

9 Fuster. The cognit: a network model of cortical representation. Int J Psychophysiol 2006; 60: 125-32.

10 Monti PM, Miranda R Jr, Nixon K, Sher KJ, Swartzwelder HS, Tapert SF, et al. Adolescence: booze, brains, and behavior. Alcohol Clin Exp Res 2005; 29: 207-20

11 Solowij N, Michie PT. Cannabis and cognitive dysfunction: parallels with endophenotypes of schizophrenia? J Psychiatry Neurosci 2007; 32: 30-52.

12 Ernst M, Korelitz KE. Cerebral maturation in adolescence: behavioral vulnerability. Encephale 2009; 35 (suppl 6): S182-9.

13 Belue RC, Howlett AC, Westlake TM, Hutchings DE. The ontogeny of cannabinoid receptors in the brain of postnatal and aging rats. Neurotoxicol Teratol 1995; 17: 25-30.

14 Medina KL, Hanson KL, Schweinsburg AD, Cohen-Zion M, Nagel BJ, Tapert SF. Neuropsychological functioning in adolescent marijuana users: subtle deficits detectable after a month of abstinence. J Int Neuropsychol Soc 2007; 13 807-20.

15 Wilson W, Mathew R, Turkington T, Hawk T, Coleman RE, Provenzale J. Brain morphological changes and early marijuana use: a magnetic resonance and positron emission tomography study. J Addict Dis 2000; 19: 1-22.

16 Collette F, Hogge M, Salmon E, Van der Linden M. Exploration of the neural substrates of executive functioning by functional neuroimaging. Neuroscience 2006; 139: 209-21.

17 American Psychiatric Association. Diagnostic and Statistical Manual of Mental Disorders (4th edn, text revision) (DSM-IV-TR). American Psychiatric Association, 1994.

18 Verdejo-Garcia AJ, Lopez-Torrecillas F, Aguilar de Arcos F, Perez-Garcia M. Differential effects of MDMA, cocaine, and cannabis use severity on distinctive components of the executive functions in polysubstance users: a multiple regression analysis. Addict Behav 2005; 30: 89-101.

19 Jager G, Ramsey NF. Long-term consequences of adolescent cannabis exposure on the development of cognition, brain structure and function: an overview of animal and human research. Curr Drug Abuse Rev 2008; 1 $114-23$.

20 Solowij N, Pesa N. Cognitive abnormalities and cannabis use [in Portuguese]. Rev Bras Psiquiatr 201032 (suppl 1): s31-40.

21 Robins LN, Wing J, Wittchen HU, Helzer JE, Babor TF, Burke J, et al. The Composite International Diagnostic Interview. An epidemiologic Instrument suitable for use in conjunction with different diagnostic systems and in different cultures. Arch Gen Psychiatry 1988; 45: 1069-77.

22 Sobel LC, Sobel MB. Time Line Follow Back: A Technique for Assessing Self Reported Alcohol Comsuption: Psychosocial And Biochemical Methods. Human Press, 1992.

23 Spreen O, Strauss E. A Compendium of Neuropsychological Tests. Oxford University Press, 1998: 326-40.

24 Heaton RK, Chelune GJ, Talley JL, Kay GG, Curtis G. Wisconsin Card Sorting Test Manual, Revised and Expanded. Psychological Assessment Resources, 1993.

25 Dubois B, Slachevsky A, Litvan I, Pillon B. The FAB: a frontal assessment battery at bedside. Neurology 2000; 55: 1621-6.

26 Wechsler D. Wais-R Manual. Psychological Corporation, 1981.

27 Spreen O, Strauss E. A Compendium of Neuropsychological Tests: Administration, Norms, and Commentary. Oxford University Press, 1998.

28 Ehrenreich $H$, Rinn $T$, Kunert HJ, Moeller MR, Poser W, Schilling L, et al. Specific attentional dysfunction in adults following early start of cannabis use. Psychopharmacology (Berl) 1999; 142: 295-301.

29 Wilson W, Mathew R, Turkington T, Hawk T, Coleman RE, Provenzale J. Brain morphological changes and early marijuana use: a magnetic resonance and positron emission tomography study. J Addict Dis 2000; 19: 1-22.

30 Pope HG Jr, Gruber AJ, Hudson Jl, Huestis MA, Yurgelun-Todd D. Neuropsychological performance in long-term cannabis users. Arch Gen Psychiatry 2001; 58: 909-15

31 Degenhardt L, Chiu WT, Sampson N, Kessler RC, Anthony RC, Angermeyer M, et al. Toward a global view of alcohol, tobacco, cannabis, and cocaine use: findings from the WHO World Mental Health Surveys. PLOS Med 2008; 5 : 1053-67.

32 Stefanis NC, Delespaul P, Henquet C, Bakoula C, Stefanis CN, Van Os J. Early adolescent cannabis exposure and positive and negative dimensions of psychosis. Addiction 2004; 99: 1333-41.

33 Gogtay N, Giedd JN, Lusk L, Hayashi KM, Greenstein D, Vaituzis AC, et al. Dynamic mapping of human cortical development during childhood through early adulthood. Proc Natl Acad Sci USA 2004; 101: 8174-9.

34 Teicher MH, Andersen SL, Hostetter JC Jr. Evidence for dopamine receptor pruning between adolescence and adulthood in striatum but not nucleus accumbens. Brain Res Dev Brain Res 1995; 89: 167-72.

35 Slawecki CJ, Ehlers CL. The effects of corticotropin-releasing factor on the cortical EEG are reduced following adolescent nicotine exposure. Neuropeptides 2003; 37: 66-73.

36 Ehlers $\mathrm{CL}$, Slutske WS, Gilder DA, Lau P. Age of first marijuana use and the occurrence of marijuana use disorders in Southwest California Indians. Pharmacol Biochem Behav 2007; 86: 290-6.

37 Fernandez-Ruiz J, Berrendero F, Hernandez ML, Ramos JA. The endogenous cannabinoid system and brain development. Trends Neurosci 2000; 23: 1420.

38 Guedj E, Allali G, Goetz C, Le Ber I, Volteau M, Lacomblez L, et al. Frontal Assessment Battery is a marker of dorsolateral and medial frontal functions: A SPECT study in frontotemporal dementia. J Neurol SCi 2008; 273: 84-7.

39 Slachevsky A, Villalpando JM, Sarazin M, Hahn-Barma V, Pillon B, Dubois B Frontal assessment battery and differential diagnosis of frontotemporal dementia and Alzheimer disease. Arch Neurol 2004; 61: 1104-7.

40 Aharonovich E, Hasin DS, Brooks AC, Liu X, Bisaga A, Nunes EV. Cognitive deficits predict low treatment retention in cocaine dependent patients. Drug Alcohol Depend 2006; 81: 313-22.

41 Lundqvist $\mathrm{T}$. Specific thought patterns in chronic cannabis smokers observed during treatment. Life Sci 1995; 56: 2141-4.

42 Hall W, Solowij N. Adverse effects of cannabis. Lancet 1998; 352: 1611-6.

43 Cunha PJ, Novaes MA. Neurocognitive assessment in alcohol abuse and dependence: implications for treatment [in Portuguese]. Rev Bras Psiquiatr 2004; 26 (suppl 1): s23-7.

44 Chang L, Yakupov R, Cloak C, Ernst T. Marijuana use is associated with a reorganized visual-attention network and cerebellar hypoactivation. Brain 2006; 129: 1096-112.

45 Ponto LL. Challenges of marijuana research. Brain 2006; 129: 1081-3.

46 Bolla KI, Eldreth DA, Matochik JA, Cadet JL. Neural substrates of faulty decisionmaking in abstinent marijuana users. Neurolmage 2005; 26: 480-92. 